\title{
O lugar dos estágios na formação de profissionais de língua estrangeira: um estudo de caso
}

\section{The place of the teaching practice in foreign language teachers education: a case study}

Alessandra Baldo ${ }^{*}$

\begin{abstract}
Resumo: Este artigo propõe uma reflexão sobre o lugar destinado aos Estágios de conclusão dos cursos de Licenciatura - Habilitação em Língua Estrangeira, por instituições de ensino da rede pública, e também sobre o papel dos estagiários e dos professores-orientadores na manutenção desse quadro, a partir da experiência da autora como professora-orientadora de Estágios em uma Universidade do estado do Rio Grande do Sul. Iniciamos com uma descrição das ementas das novas disciplinas de Estágio do projeto curricular da Faculdade de Letras da Universidade a fim de analisar as razões subjacentes às modificações levadas a termo nas disciplinas. Tanto a descrição como a análise têm como pano de fundo as políticas nacionais para o ensino de língua estrangeira e o contexto de ensino-aprendizagem de línguas nas escolas públicas. Além disso, possíveis consequências dessas modificações para a formação do profissional de língua estrangeira serão levantadas.

Palavras-chave: Estágio de língua estrangeira. Currículo. Políticas nacionais para ensino-aprendizagem de LE. Formação de professores de lingua.

Abstract: This article proposes a reflection on the status attributed by public schools to the compulsory teacher training taken by undergraduate students of Languages, as well as the role played by students-teachers and foreign language teacher training supervisors in the matter, based on the author's experience as a teacher training supervisor in a university in the south of Brazil. The article starts with a description of the new teacher training courses set by the Language Institute of the university, and is followed by an analysis of the underlying reasons for the changes taken into effect. Both the description and the analysis take into consideration (i) the national policies to foreign language (FL) teaching and learning and (ii) the general context in which foreign languages are taught in public schools. Possible outcomes deriving from such changes are also discussed.

Keywords: FL teacher education. Curriculum. National policies to FL teaching and learning. Language teachers' professional development.
\end{abstract}

*Doutora em Linguística, Universidade Federal de Pelotas - E-mail: lelabaldo@terra.com.br 
Alessandra Baldo

\section{Introdução}

Os estágios de conclusão de curso se revestem de uma importância única nos cursos de Licenciatura, já que possibilitam, para muitos estagiários, o primeiro contato com a docência e com um de seus possíveis ambientes de trabalho. Desse modo, seria de esperar que estes pudessem encontrar condições favoráveis para a realização de sua prática docente nas instituições das redes de Ensino Fundamental e/ou de Ensino Médio. No entanto, os constantes obstáculos enfrentados pelos licenciandos em Letras no que diz respeito à realização de seus estágios nas escolas têm colocado em xeque, em determinadas situações, até mesmo a validade de sua realização.

Neste contexto caótico, em que o estagiário é muitas vezes identificado como um indivíduo que perturba o andamento dos trimestres escolares, e não como um futuro colega de profissão que pode não somente aprender com o professor titular da disciplina como também (por que não?) contribuir para a formação profissional deste, novas formas de realização do estágio curricular foram buscadas na Universidade em que atuo como professora-orientadora de Estágio de Língua Inglesa. A mais importante delas foi concretizada em 2008, através de três novas disciplinas que, juntas, constituem a prática de estágio do licenciando: Estágio de Observação, Estágio de Intervenção Comunitária e Estágio de Regência. Isto colocado, o primeiro objetivo deste artigo é proceder a uma descrição da proposta das disciplinas mediante o estudo de suas ementas, a fim de ser possível analisar (i) as razões que levaram às modificações efetuadas, como também (ii) as possíveis influências dessas modificações na formação do futuro profissional de Letras.

Para tanto, organizamos o trabalho em três partes. Na primeira, apresentamos as ementas das novas disciplinas de Estágio - Língua Estrangeira, contrapondo-as com as disciplinas do currículo em extinção. Na segunda, sintetizamos as propostas do governo federal para o ensino de Língua Estrangeira à luz de seus documentos mais recentes, e buscamos traçar um breve panorama das condições de ensino-aprendizagem dessa disciplina na maioria das escolas de Ensino Fundamental e Médio. As informações apresentadas servem de base para a última parte do trabalho, na qual buscamos avaliar as motivações atreladas ao ajuste das disciplinas de Estágio, como também as possíveis consequências desse ajuste para a formação do estudante de Letras. 
O lugar dos estágios na formação de profissionais de Língua Estrangeira: um estudo de caso.

\section{Currículo de Letras: Estágio de Língua Estrangeira}

Os currículos dos cursos de Licenciatura em Letras, em todas as suas diferentes habilitações em Língua Estrangeira - Inglês, Espanhol, Francês e Alemão - foram recentemente modificados. Um dos objetivos principais dos idealizadores do novo currículo - e, certamente, um dos maiores desafios era o de diminuir em um ano a extensão dos cursos, passando de cinco para quatro anos de duração, e manter, ao mesmo tempo, a qualidade de ensino. Num primeiro momento, as quatro disciplinas de Estágio existentes - as duas primeiras destinadas ao ensino de Língua Estrangeira (LE) no Ensino Fundamental, e as duas últimas, no Ensino Médio - não sofreram alteração, mas a necessidade de inclusão de Libras, conforme o decreto $n^{0} 5.626$, de 22 de dezembro de 2005, acarretou uma nova estrutura de realização dos estágios de conclusão de curso, passando de quatro para três disciplinas - Estágio de Observação, Estágio de Intervenção e Estágio de Prática - as quais não mais preveem a divisão entre estágios para o Ensino Fundamental e Médio.

É senso comum que os estágios, independentemente do curso de graduação, têm um papel central na formação do universitário. Essa importância se deve a vários fatores, mas nos atemos aqui a dois que julgamos os principais: primeiro, a possibilidade longamente aguardada pelos estudantes de integrar os princípios teóricos estudados na universidade com experiências práticas; segundo, e não menos importante, a oportunidade de entrar em contato com o provável futuro ambiente de trabalho, familiarizando-se com a estrutura típica do local, com suas convenções, regras de comportamento e rotinas.

O currículo em extinção do curso de Letras, no que tange aos Estágios, sempre procurou contemplar essas duas finalidades, como se pode notar pelas ementas das disciplinas transcritas a seguir.

Estágios I e III: discussão e reflexão sobre o ensino da língua inglesa, a partir da observação de um contexto autêntico de ensino e aprendizagem para alunos do ensino fundamental (Estágio I)/ ensino médio (Estágio III).

\footnotetext{
Embora o foco deste artigo sejam os Estágios de Língua Estrangeira, em especial Língua Inglesa, nos quais atuo como professora-orientadora, as disciplinas de Estágio da Licenciatura em Letras - Habilitação em Língua Portuguesa, são as mesmas, já que a filosofia de estágio é única para todas as habilitações.

Uniletras, Ponta Grossa, v. 32, n. 1, p. 47-59, jan./ jun. 2010 
Alessandra Baldo

Estágios II e IV: exercícios da docência de língua inglesa em contexto autêntico de ensino e aprendizagem para alunos do ensino fundamental (Estágio II)/ ensino médio (Estágio IV).

Como se percebe, a oportunidade de contato com um dos possíveis ambientes de trabalho do estudante é coberta pela tentativa de "desenvolver a sua capacidade de interação com o professor em serviço, bem como de observação e de reflexão crítica acerca das aulas" (Estágios I e II). Já a oportunidade de integração entre teoria e prática aparece claramente no objetivo dos Estágios II e IV, no sentido de criar condições para que o professor em formação assuma o papel de docente e, em especial, que este esteja em "consonância com os princípios teóricos e metodológicos desenvolvidos durante o curso de graduação".

Tanto a busca da integração teoria e prática como a possibilidade de contato com o futuro ambiente profissional são abarcados pelo ajuste curricular de 2008, conforme documentam as ementas das três novas disciplinas de Estágio:

Estágio de Observação: atividades colaborativas em ambientes escolares das redes de ensino fundamental e médio e/ou atividades de pesquisa aplicada ou de campo de contextos escolares da rede pública dos ensinos fundamental e/ou médio.

Estágio de Intervenção Comunitária: atividades de intervenção na comunidade escolar, mediante projetos de extensão ou ensino, atendendo a demandas específicas de seus pares (alunos, pais de alunos, funcionários), ou, ainda, a demandas provocadas pelo interesse do curso de Letras.

Estágio de Regência : atividades de docência supervisionada, formal e não formal, em contextos escolares da rede pública de ensino fundamental ou médio ou em outros contextos em que a prática de ensino desenvolva-se de acordo com métodos e procedimentos pedagógicos relevantes à formação do licenciando em Letras (Ajuste Curricular 2008, Faculdade de Letras).

Uma vez que os dois objetivos entendidos aqui como os mais relevantes dos Estágios são encontrados nas duas propostas curriculares, é possível concluir que mesmo o corte de uma disciplina não chegou a 
resultar, pelo menos na teoria, em prejuízo para a formação do licenciando em Letras.

Apesar das semelhanças, há, no entanto, uma diferença de escopo com relação ao campo de atuação entre as duas propostas que merece atenção. Em cada uma das ementas das disciplinas de Estágio provenientes do ajuste curricular, tal diferença pode ser constatada em relação ao emprego das palavras de ligação elou (Estágio de Observação), ou somente ou (Estágios de Intervenção Comunitária e de Regência). Assim, enquanto no currículo antigo os ementários dos Estágios I e III restringiam o conceito de "contex to autêntico de ensino-aprendizagem" a escolas de Ensino Fundamental (Estágio I) e Médio (Estágio III), mais especificamente às aulas de LE que aconteciam em tais ambientes, o Estágio I em voga amplia o conceito de observação de tal forma (cf. transcrição da ementa) que desvendá-lo pode ser uma tarefa complexa para profissionais pouco familiarizados com a filosofia do curso de Letras relativa aos estágios de conclusão.

Coerentemente, esta ampliação da definição de contexto autêntico de ensino-aprendizagem também é testemunhada quando comparamos as ementas das disciplinas de Estágios II e IV do currículo antigo - destinadas ao exercício da docência no Ensino Fundamental (Estágio II) e no Ensino Médio (Estágio IV) - com as ementas dos Esstágios de Intervenção Comunitária e de Regência da proposta de 2008. Enquanto as duas primeiras limitam a prática de ensino "para alunos do ensino fundamental/médio", as duas últimas preveem uma comunidade mais extensa, como pais de alunos e funcionários das escolas ou, ainda, outras alternativas, vagamente definidas como "demandas provocadas pelo interesse do curso de Letras". Com relação ao Estágio de Regência, além da rede pública de Ensino Fundamental ou Médio, outros contextos estão previstos, desde que estes se mostrem relevantes à formação do graduando.

Nas duas próximas seções, buscaremos compreender as causas adicionais, além da necessidade de inclusão das disciplinas de Libras I e II,

\footnotetext{
${ }^{2}$ Na prática não há ainda como avaliar, pois a primeira turma a realizar seu estágio pela nova proposta está cursando Estágio I neste semestre.

${ }^{3}$ Ainda que não haja uma correspondência unívoca entre as duas disciplinas do currículo em extinção (Estágios II e IV) e as duas da nova proposta (Estágio de Intervenção Comunitária e de Regência), elas se aproximam na medida em que todas objetivam (i) a preparação de materiais e (ii) a prática docente. 
Alessandra Baldo

que motivaram os ajustes curriculares das disciplinas de Estágio - Língua Estrangeira, discutindo primeiramente questões relativas à política nacional de ensino de LE.

\section{Políticas de Ensino-Aprendizagem de LE e Contexto Educacional}

Essa seção está organizada em duas partes principais. Na primeira, procedemos a uma síntese das propostas do governo federal para o ensino de LE, conforme dispostas nos seus documentos mais recentes, a Lei de Diretrizes e Bases da Educação, de 1996 (LDB 9.394/96), os Parâmetros Curriculares Nacionais para o Ensino Fundamental, de 1998, e para o Ensino Médio, de 1999, e uma reelaboração dos Parâmetros para o Ensino Médio, que será referida aqui como os PCN-EM+, conforme sugestão de Menegazzo (2006). Na segunda, discorremos sobre a compatibilidade das diretrizes apresentadas com o contexto real de ensino de LE na maioria das escolas brasileiras.

A partir da LDB 9.394/96, o ensino de uma língua estrangeira passa a ser obrigatório tanto no Ensino Fundamental como no Médio, e a escolha deve levar em conta características regionais e/ou as possibilidades da instituição de ensino. A oferta de uma segunda língua estrangeira, em caráter optativo, é recomendada, mas a decisão final cabe à escola. Esta mesma orientação é continuada pelos PCNs, os quais promovem a sua inclusão ao conjunto de disciplinas que compõem a área de Linguagem, Códigos e suas Tecnologias. Tal inclusão, na verdade, pode ser entendida como o principal avanço dos novos parâmetros, pois deixa transparecer o entendimento, por parte do Ministério de Educação e Cultura, de que a língua estrangeira é:

parte indissociável no conjunto de conhecimentos essenciais que permitem agir discursivamente num mundo globalizado, isto é, envolver-se e envolver outros no discurso". (MENEGAZZO, 2006, p. 15).

Em conformidade com tal entendimento, os PCNs-LE ressaltam que a aprendizagem de uma língua estrangeira é um direito de todo cidadão e uma responsabilidade que cabe à escola. Apregoam que o objetivo é 
levar o aluno a atingir a competência comunicativa na língua estrangeira, a qual é alcançada pelo desenvolvimento de conhecimentos de natureza linguística, sociolinguística, discursiva e estratégica. Para tanto, propõem uma metodologia de ensino de base comunicativa, que leve em conta a necessidade de o aluno conhecer a língua estrangeira como instrumento de comunicação e de reflexão sobre a linguagem, conforme transcrição a seguir ${ }^{4}$.

[...] deixa de ter sentido o aprendizado de línguas que objetiva apenas o conhecimento metalinguístico e o domínio consciente de regras gramaticais que permitem, quando muito, alcançar resultados puramente medianos em exames escritos. Esse tipo de ensino [...] cede lugar, na perspectiva atual, a uma modalidade de curso que tem como princípio geral levar o aluno a comunicar-se de maneira adequada em diferentes situações da vida cotidiana. (BRASIL, 1998, p. 151).

Ainda que possa parecer estranho, orientação diversa é encontrada nos PCN-EM+(2002), os quais estabelecem como prioritários três conteúdos a serem trabalhados pelo professor de LE: estrutura linguística, aquisição de repertório vocabular e leitura e interpretação textual (p. 103). Como não é difícil concluir que somente esses três conteúdos não instrumentalizarão o aluno para que ele consiga "comunicar-se de maneira adequada em diferentes situações da vida cotidiana" - o mais provável, na verdade, é que ele consiga, "quando muito, alcançar resultados puramente medianos em exames escritos" (BRASIL, 1998, p. 151) - as primeiras indagações que cabem ao professor de LE são: "Quais são, afinal, os parâmetros a serem seguidos no que diz respeito ao ensino-aprendizagem de LE em âmbito nacional? Eles são diferentes para o Ensino Fundamental e para o Ensino Médio? Em caso afirmativo, a que se deve essa diferença? Quais são as prioridades estabelecidas pelos $\mathrm{PCNs}$ em termos de habilidades e competências em LE a serem desenvolvidas com os alunos? Como devo organizar meus planos de curso/aula em função de tais prioridades?"

Além desta questão teórica de importância central, o professor de LE, uma vez tendo escolhido seguir ou uma metodologia comunicativa que

\footnotetext{
${ }^{4}$ Essa proposta, no entanto, é confusa, com algumas seções do documento ressaltando a importância do uso da língua estrangeira em diferentes situações, e outras priorizando a habilidade de leitura em LE. Para uma discussão mais aprofundada sobre o tópico, ver Paiva (2003) e Dourado (2008). 
contemple as quatro habilidades ou uma abordagem que contemple especificamente o ensino de leitura, enfrenta todas as já mais do que conhecidas e comentadas condições desfavoráveis - e, naturalmente, desencorajadoras para o ensino-aprendizagem de uma língua estrangeira no ambiente escolar. Entre elas, citamos especialmente as classes numerosas e heterogêneas com relação ao conhecimento da língua estrangeira e o número cada vez mais inexpressivo de horas/aula dedicadas a essa disciplina, o que impossibilita ao aluno progredir significativamente no seu conhecimento da língua. As consequências dessa inércia no processo de ensino-aprendizagem estão refletidas nos papéis do professor e do aluno de LE em muitas escolas de nosso país: ao primeiro cabe repetir os mesmos conteúdos ano após ano, já que o aluno não dispõe de tempo suficiente em sala de aula para internalizá-los e empregá-los em situações comunicativas relevantes; ao segundo, cabe assistir às aulas que lhe são oferecidas, ainda que seu interesse seja pequeno e/ou tenha consciência das limitações da disciplina no que diz respeito ao processo de aquisição da língua-alvo.

Nesse contexto, o aumento do número de horas/aula, na nossa visão, assume um caráter fundamental se o que se almeja é de fato que os estudantes adquiram uma maior proficiência em uma língua estrangeira. Naturalmente não entendemos ser esse o único fator que necessita de revisão na política de ensino-aprendizagem de LEs, mas certamente é o primeiro: sem um número maior de horas/aula semanais de contato com a língua-alvo, debates sobre a metodologia a ser empregada nas aulas, sobre as habilidades a serem enfatizadas, sobre os objetivos do ensino-aprendizagem de LE, caem todos por terra.

Levando isto em consideração, a aceitação da lei 1.1161/05, que prevê a oferta obrigatória de Língua Espanhola para o Ensino Médio em toda a rede pública de ensino até o ano de 2010, não é tarefa fácil. Primeiro, porque vai de encontro à filosofia preconizada tanto pela LDB 9.394/96 como pelos PCNs no que tange à possibilidade de escolha da LE a ser ofertada nas escolas. Segundo, e mais importante, porque a solução encontrada por muitas escolas de Ensino Médio para contemplar o ensino da Língua Espanhola sem deixar de ofertar aulas de Língua Inglesa foi restringir a carga horária de cada uma delas a uma hora/aula semanal, nos casos em que a carga horária das LEs era previamente de duas horas/aula semanais. Em outras situações ainda, a opção foi oferecer 
O lugar dos estágios na formação de profissionais de Língua Estrangeira: um estudo de caso.

Língua Inglesa no primeiro ano do Ensino Médio e Língua Espanhola nos dois anos seguintes, especialmente nas escolas cuja carga horária destinada à LE na grade de horários era de uma hora/aula semanal. Embora ainda não seja possível prever os resultados de tal medida, é fácil notar que ela está na contramão da orientação vigente para o ensino de LE, decorrente de décadas de pesquisas e estudos aplicados na área.

Independentemente das motivações que levaram o atual governo a aprovar tal lei, a questão que gostaríamos de levantar aqui é a de que a introdução da Língua Espanhola nas escolas inicia com os mesmos problemas enfrentados pelas outras línguas estrangeiras. Assim, parece-nos adequado refletir aqui em que medida o retorno do investimento que está sendo feito pelo Ministério da Educação para a oferta de Língua Espanhola (formação de professores, compra de material didático) será satisfatório, considerando-se que os vários aspectos desfavoráveis para o ensino-aprendizado de uma LE continuam presentes no ambiente escolar.

\section{Adequação dos Estágios de Conclusão de Curso - LE ao Con- texto Escolar}

Esperamos que a breve síntese sobre as medidas mais recentes do governo federal com relação às políticas educacionais nacionais, em específico às políticas para o ensino-aprendizagem de LE, como também sobre o status das LEs nas escolas brasileiras, tenha possibilitado ao leitor um panorama sobre o contexto do ensino dessa disciplina nas escolas públicas. Como vimos, além de não haver clareza com relação aos parâmetros nacionais que o professor deve adotar para o planejamento de suas aulas, este enfrenta dificuldades de toda a sorte na prática docente, dadas as condições de ensino de LE no contexto escolar.

Pois é a este professor, que é requisitado a (i) trabalhar em salas excessivamente numerosas e, ao mesmo tempo, ter habilidade de lidar com as individualidades de cada aluno; (ii) adequar seus princípios metodológicos aos recursos da escola, bem como seus conteúdos ao número limitado de horas;

\footnotetext{
${ }^{5}$ E tais razões, conforme argumentado por Jaeger (2009), podem ser bastante diferentes do que as comumente divulgadas pelo governo federal e pela mídia.

Uniletras, Ponta Grossa, v. 32, n. 1, p. 47-59, jan./ jun. 2010 
(iii) lidar com grupos heterogêneos no conhecimento da língua estrangeira, que o professor responsável pelas disciplinas de Estágio de Língua Estrangeira recorre sempre que necessita que seus alunos cumpram o número de horas-práticas determinado pelo currículo, seja por meio de observações, seja por meio da prática docente. Nesse contexto, não é de surpreender que, ao contatar recentemente as escolas para averiguar a possibilidade de realização de estágio, tenhamos ouvido dos Coordenadores de Estágios respostas como as que se seguem:

Eu estou sozinha na coordenação, então vamos receber bem poucos estagiários este semestre. Não sei te dizer quantos, porque ainda não recebi as orientações da $\mathrm{CRE}^{6}$, mas sei que serão poucos. O estagiário dá muito trabalho...

Neste semestre não estamos recebendo alunos para a realização do estágio de observação, somente para o de prática.

Estamos disponíveis para o estágio, desde que o aluno inicie e acabe um trimestre, esteja com a turma desde o início até a avaliação final.

Estamos com muita falta de professores, então este trimestre decidimos que não teremos estagiários em nossa escola.

A falta de uma política de estágios nas escolas pode ser vista como um reflexo dos problemas estruturais que fazem parte do cotidiano dessas há bastante tempo, como quadro insuficiente de funcionários/professores e docentes sobrecarregados de trabalho e sem disposição e/ou tempo livre para "adotar" um estagiário. Embora nossa tendência, enquanto professores-orientadores de Estágios na Universidade, seja criticar essa postura, a qual podemos entender como pouco colaborativa em um primeiro momento, a crítica, nesse caso, parece ser injusta.

Este ambiente de frequentes obstáculos para a realização de estágios nas escolas constituiu uma das principais motivações para a nova filosofia do processo de estágio curricular dos cursos de Letras. Com a possibilidade de estender o conceito de "contexto autêntico de ensino-aprendizagem" para "atividades de pesquisa aplicada ou de campo de contextos escolares da rede pública dos ensinos fundamental e/ou médio", "projetos de extensão ou ensino,

\footnotetext{
${ }^{6}$ Sigla referente à Coordenadoria Regional de Educação. 
O lugar dos estágios na formação de profissionais de Língua Estrangeira: um estudo de caso.

atendendo a demandas específicas da comunidade escolar", etc., procurou-se aumentar a gama de opções dos modos e locais de realização dos estágios de conclusão de curso.

Isso não significa, contudo, que o corpo docente da Faculdade acredite que as alternativas de concretização de estágio oferecidas pelo novo projeto curricular possam ser comparadas ao estágio efetuado em escolas. $\mathrm{O}$ ambiente escolar continua sendo entendido como o ideal para os estágios de conclusão de curso, tanto por representar o provável futuro ambiente de trabalho de muitos dos estagiários, como por possibilitar a aplicação de vários conceitos estudados e debatidos ao longo do curso de graduação dos licenciados, como planejamento de aula para pré-adolescentes e adolescentes, estratégias de gerenciamento de salas de aula numerosas, prática de trabalho colaborativo com o professor-titular, entre outros.

Assim, ao privar o graduando dessa experiência, entendemos que uma das possíveis consequências de tal ajuste curricular seja formar um profissional menos qualificado em termos didático-pedagógicos. O comprometimento dessa qualificação, neste sentido, estaria atrelado à distância existente entre as condições em que o estágio do licenciando foi realizado e as condições geralmente verificadas nas aulas de LE das escolas da rede pública de ensino.

\section{Considerações Finais}

Neste artigo, realizamos inicialmente (i) uma análise das novas ementas das disciplinas de Estágio - Habilitação em Língua Estrangeira implementadas no ajuste curricular efetuado em 2008 pela Faculdade de Letras de uma Universidade do estado do Rio Grande do Sul, e (ii) uma síntese das políticas federais para o ensino de LE, tendo como pano de fundo o contex to educacional brasileiro. Tanto a análise como a síntese tiveram como primeiro objetivo fornecer subsídios para compreender as razões subjacentes às modificações efetuadas nessas disciplinas. Como foi possível constatar, elas podem ser atribuídas, em grande medida, aos obstáculos cada vez mais difíceis de serem ultrapassados pelos licenciandos a fim de conseguirem realizar o que deveria ser uma experiência de docência compartilhada, ou seja, realizada através da troca contínua de informações e conhecimentos entre a escola, na figura do professor titular e do coordenador de área de Estágios, o estagiário

Uniletras, Ponta Grossa, v. 32, n. 1, p. 47-59, jan./ jun. 2010 
Alessandra Baldo

e a Universidade, na figura do professor- orientador e do Colegiado do Curso.

O segundo objetivo do estudo comparativo das ementas das novas disciplinas e das considerações sobre o contexto de ensino-aprendizagem de LE nas escolas públicas era o de possibilitar uma reflexão sobre as possíveis consequências que a nova estrutura do Estágio de Língua Estrangeira da Faculdade de Letras poderia trazer para o graduando no que diz respeito à sua formação profissional. Nesse sentido, mesmo considerando justificáveis as mudanças efetuadas nas disciplinas de Estágio, o que causa apreensão é a possibilidade de os estágios alternativos, ou seja, os que não seriam concretizados nas escolas ou que não teriam os alunos de Ensino Fundamental e/ou Médio como público-alvo principal, virem a tornar-se a regra e não a exceção, dada a maior facilidade com que poderiam ser viabilizados, especialmente se considerarmos o tempo relativamente curto que, em geral, graduandos e professores-orientadores possuem para organizar os estágios. Nesse contexto, $\mathrm{o}$ raciocínio seria, de forma aproximada, o seguinte: já que há muitos obstáculos a serem superados para a realização dos estágios de LE nas escolas, então o mais prático é procurar formas alternativas, como cursos de extensão e projetos de ensino.

Assim, uma possível atitude de acomodação e conformismo, ao invés de uma atitude de transformação, representaria o efeito mais grave dos ajustes propostos, pois, ao procurar desviar as diferentes situações problemáticas que dificultam a realização de estágios nas escolas, a Faculdade de Letras, através de seus docentes e estagiários, estaria deixando de contribuir para propostas de soluções de tais problemas, as quais não somente seriam de grande valor para o profissional em formação, mas também representariam a possibilidade de viabilização de um ambiente mais profícuo para a realização de futuros estágios de docência compartilhados.

Portanto, cabe pensarmos nas barreiras criadas pelos próprios estagiários e pela própria Universidade para a concretização dos estágios nas escolas da rede pública, considerando que as barreiras criadas pela falta de recursos materiais e humanos das escolas da rede pública já foram mencionadas. Nesse contexto, o desabafo de uma professora responsável pela Coordenação dos Estágios de uma escola de Ensino Fundamental e Médio da cidade nos parece bastante esclarecedor: "Eu me sinto sozinha aqui, sem retorno do estagiário e nem da Universidade". Frente a essa declaração, a questão merecedora de atenção especial parece ser a seguinte: se nem o estagiário e nem a Universi- 
O lugar dos estágios na formação de profissionais de Língua Estrangeira: um estudo de caso.

dade têm conseguido operacionalizar o estágio como um processo de troca de informações e conhecimentos entre as partes envolvidas, pelo menos no parecer dessa coordenadora, não é injusto pretender que a escola o faça? Ainda que a experiência que obtivemos pelo contato com escolas públicas nos permita argumentar que essa ainda não se apercebeu das possíveis contribuições que podem advir de uma relação de trabalho efetiva entre professor-titular e estagiário, essa mesma experiência nos possibilita sustentar a hipótese de que tal despercebimento se deve, em grande medida, a uma ausência de políticas de ensino-aprendizagem de LEs coerentes e comprometidas de fato com a aquisição da língua-alvo pelo aprendiz. Nesse sentido, o aliado natural para superar o descaso com as línguas estrangeiras nas escolas da rede pública deveria ser a Universidade, representada também pelo estagiário. Que a escola não se dê conta disso, é até aceitável. Que a Universidade não se dê conta disso, não.

\section{Referências}

BRASIL. MINISTÉRIO DA EDUCAÇÃO, SECRETARIA DE EDUCAÇÃO MÉDIA E TECNOLÓGICA. Parâmetros Curriculares Nacionais: Ensino Fundamental. Brasília, Ministério da Educação, 1998.

Parâmetros Curriculares Nacionais: Ensino Médio. Brasília, Ministério da Educação, 1999.

PCN+ Ensino Médio - linguagens, códigos e suas tecnologias. Brasília. MEC, SEMTEC, 2002.

DOURADO, M. R. S. Dez anos de PCNs de Língua Estrangeira sem Avaliação dos Livros Didáticos pelo PNLD. Linguagem em (Dis)curso, v.8, n.1, p. 1-11, jan/abril 2008.

JAEGER, D. Língua espanhola nas escolas brasileiras, integração e política lingüística: reflexões em torno da aprovação da Lei 11161/05. Revista Espaço Acadêmico, 2009, p. 31-36. Disponível em: 〈http://periodicos.uem.br/ojs/index.php/EspacoAcademico/index>.

MENEGAZZO, M. A. Os PCNEM e PCN+ de Língua Estrangeira: sugestões aplicáveis? Dissertação de Mestrado. Cap. 2. Universidade Estadual de Londrina, Paraná, Programa de Pós-Graduação em Letras, p. 11-22, 2006.

PAIVA, V. L. M. A LDB e a legislação vigente sobre o ensino e a formação de professor de língua inglesa. In: STEVENS, C. M. T.; CUNHA, M. J. Caminhos e colheitas: ensino e pesquisa na área de inglês no Brasil. Brasília: UnB, p. 53-84, 2003.

Recebido para publicação em 01 jul. 2010.

Aceito para publicação em 05 jul. 2010.

Uniletras, Ponta Grossa, v. 32, n. 1, p. 47-59, jan./ jun. 2010 